\title{
Treatment of vaginal agenesis using a modified McIndoe technique: Long-term follow-up of 23 patients and a literature review
}

\author{
Ercan Bastu $M D^{1}$, Suleyman Engin Akhan $\mathrm{MD}^{1}$, Mehmet Firat Mutlu MD², \\ Asli Nehir $M D^{1}$, Harika Yumru $M D^{1}$, Emre Hocaoglu $M D^{3}$, Funda Gungor-Ugurlucan $M D^{1}$
}

\begin{abstract}
E Bastu, SE Akhan, MF Mutlu, et al. Treatment of vaginal agenesis using a modified McIndoe technique: Long-term follow-up of 23 patients and a literature review. Can J Plast Surg 2012;20(4): $241-244$.
\end{abstract}

BACKGROUND: Congenital vaginal agenesis is a rare malformation with an incidence of one in 4000 to 5000 female newborns. The purpose of vaginal agenesis treatment is not only to create an adequate passageway for penetration but also to facilitate satisfactory sexual intercourse.

OBJECTIVE: To present the results of a modified McIndoe technique with respect to sexual function, vaginal length and complication rates in patients with vaginal agenesis.

METHODS: Between 2002 and 2010, 23 patients with vaginal agenesis were admitted to the Gynecology Clinic of Istanbul University School of Medicine (Istanbul, Turkey) for vaginal reconstruction. All patients underwent a modified McIndoe procedure. The long-term results with a followup period ranging from 18 to 118 months are presented.

RESULTS: The postoperative mean vaginal length was $8.4 \mathrm{~cm}$ (range $6 \mathrm{~cm}$ to $11 \mathrm{~cm}$ ) in 19 patients who used the mould regularly. Among 14 patients who used the mould regularly and had partners, only one experienced severe pain during intercourse and 13 reported that they were engaging in satisfactory sexual activity with mild or no pain, and with good mucosal sensitivity. Conversely, two of three patients who used the mould irregularly experienced severe pain during intercourse and had a mean vaginal length of $6 \mathrm{~cm}$ (range $4 \mathrm{~cm}$ to $8 \mathrm{~cm}$ ).

CONCLUSION: The findings suggest that a modified McIndoe technique is a simple, effective procedure for the treatment of vaginal agenesis; however, proper mould use after surgery remains the cornerstone of the treatment.

Key Words: McIndoe technique; Vaginal agenesis; Vaginoplasty

Congenital vaginal agenesis is a rare malformation that has an incidence of one in 4000 to 5000 female newborns (1). Although vaginal agenesis is most commonly encoutered in women with Rokitansky syndrome (Mayer-Rokitansky-Kuster-Hauser syndrome or Müllerian aplasia) (2) and androgen insensitivity syndrome (AIS), it can also present in patients with Turner syndrome, Morris syndrome and as a part of combined congenital defects. Patients with Rokitansky syndrome and AIS have normal secondary sex characteristics and external genitalia. These patients present with primary amenorrhea typically in adolescence. A blind or absent vagina is discovered during gynecological examination in such patients.

The purpose of the treatment is not only to create an adequate passageway for penetration but also to facilitate satisfactory sexual intercourse. There are several nonsurgical and surgical treatment techniques described in the literature for treatment of vaginal agenesis. Nonsurgical options include vaginal dilation with a dilator, while surgical options include the Vecchietti procedure (3-5), Davydov technique (6), McIndoe technique (7) and intestinal vaginoplasty. The first vaginal reconstruction was performed by Amussat in 1832 (8). In 1872,

\section{Le traitement de l'agénésie vaginale au moyen d'une technique de McIndoe modifiée : le suivi à long terme de 23 patients et une analyse bibliographique}

HISTORIQUE : L'agénésie vaginale congénitale est une malformation rare à l'incidence de un cas sur 4000 à 5000 nouveau-nés de sexe féminin. Le traitement de l'agénésie vaginale vise non seulement à créer un passage suffisant pour la pénétration, mais également à favoriser des relations sexuelles satisfaisantes.

OBJECTIF : Présenter les résultats d'une technique de McIndoe modifiée à l'égard de la fonction sexuelle, de la profondeur du vagin et des taux de complication chez les patients ayant une agénésie vaginale.

MÉTHODOLOGIE : De 2002 à 2010, 23 patientes ayant une agénésie vaginale ont été hospitalisées à la clinique de gynécologie de la faculté de médecine de l'université d'Istanbul, en Turquie, pour subir une reconstruction vaginale. Toutes les patientes ont subi une intervention de McIndoe modifiée. Les chercheurs présentent les résultats à long terme de cette intervention, après une période de suivi de 18 à 118 mois.

RÉSULTATS : Le vagin avait une profondeur moyenne de $8,4 \mathrm{~cm}$ après l'opération, variant de $6 \mathrm{~cm}$ à $11 \mathrm{~cm}$ chez les 19 patientes qui utilisaient le moule régulièrement. Chez les 14 patientes qui utilisaient le moule régulièrement et avaient des partenaires, une seule a ressenti des douleurs marquées pendant les relations sexuelles, et 13 ont déclaré avoir des relations sexuelles satisfaisantes associées à des douleurs légères, sinon inexistantes, et à une bonne sensibilité muqueuse. Par contre, deux des trois patientes qui n'utilisaient pas le moule régulièrement ont ressenti des douleurs marquées pendant les relations sexuelles, et leur vagin avait une profondeur moyenne de $6 \mathrm{~cm}$ (plage de $4 \mathrm{~cm}$ à $8 \mathrm{~cm}$ ).

CONCLUSION : D'après les observations, la technique de McIndoe modifiée est une intervention simple et efficace pour traiter l'agénésie vaginale, mais une bonne utilisation des moules après l'opération demeure la pierre angulaire du traitement.

Heppner was the first surgeon who used split thickness skin grafting for vaginoplasty (9). Baldwin used a vascularized segment of ileum to create a new vaginal canal in 1908, while Wagner used sigmoid colon for the same purpose in 1927 (10). The McIndoe technique was first described in 1938 by Bainster and McIndoe (9). Despite the existence of several alternative methods, there is still no consensus regarding the best option for surgical correction

The aim of our study was to present the results of a modified McIndoe technique with respect to sexual function, vaginal length and complication rates in patients with vaginal agenesis.

\section{METHODS}

Between 2002 and 2010, 62 patients with vaginal agenesis were admitted to Gynecology Clinic at the Istanbul University School of Medicine (Istanbul, Turkey) for vaginal reconstruction. Follow-up of 23 patients was accomplished over a period of eight years. An additional 39 patients, whose preoperative findings were evaluated from their initial patient files, were lost to follow-up for various reasons (moved, no contact or patient refusal). Preoperatively, all patients

${ }^{1}$ Department of Obstetrics and Gynecology, Istanbul University School of Medicine, Istanbul; ${ }^{2}$ Department of Obstetrics and Gynecology, Gazi

University School of Medicine, Ankara; ${ }^{3}$ Department of Plastic and Reconstructive Surgery, Istanbul University School of Medicine, Istanbul,

Turkey

Correspondence: Dr Ercan Bastu, Istanbul University School of Medicine, Department of Obstetrics and Gynecology, Division of Infertility,

Capa 34093, Istanbul, Turkey. Telephone 90-532-413-4195, e-mail ercan.bastu@istanbul.edu.tr 


\begin{tabular}{|c|c|}
\hline \multicolumn{2}{|l|}{ Overview of patients } \\
\hline Anatomy & Patients, $\mathrm{n}$ \\
\hline \multicolumn{2}{|l|}{ Vaginal aplasia } \\
\hline Total & 4 \\
\hline Partial & 19 \\
\hline \multicolumn{2}{|l|}{ External genitalia } \\
\hline Normal & 22 \\
\hline Clitoromegaly & 1 \\
\hline \multicolumn{2}{|l|}{ Uterus and fallopian tubes } \\
\hline Normal & 2 \\
\hline Absent & 20 \\
\hline Rudimentary & 1 \\
\hline \multicolumn{2}{|l|}{ Ovaries } \\
\hline Normal & 21 \\
\hline$<2$ & 2 \\
\hline \multicolumn{2}{|l|}{ Skeletal anomalies } \\
\hline Klippel-Feil syndrome & 1 \\
\hline
\end{tabular}

underwent clinical examination, pelvic ultrasonography, vaginometry, pelvic magnetic resonance imaging to evaluate pelvic organs and the urinary system, and x-rays to evaluate potential skeletal anomalies. Diagnosis was confirmed with karyotyping when needed.

The preferred method for vaginal reconstruction was the modified McIndoe technique. The surgical team included surgeons from the departments of obstetrics and gynecology and plastic and reconstructive surgery. All patients were operated on under general anesthesia in the lithotomy position with urinary catheterization. Before starting the surgery, a first-generation cephalosporin was administered as a prophylactic antibiotic. The gynecologists initiated the surgery. Through an $\mathrm{H}$-shaped incision in the perineum, a vesicorectal space was created by blunt, and occasionally sharp, dissection between the urethra, bladder and the rectum. The Douglas pouch represented the upper limit of dissection. Following meticulous hemostasis of this neovaginal space, the plastic surgeons took over the surgery. A Humby's knife was used to harvest a split-thickness skin graft from the gluteal region. The graft was perforated in multiple places with a scalpel and sewn with absorbable sutures over a smooth-surfaced glass mould, which was then inserted into the preformed neovaginal cavity. Finally, the free edge of the skin graft was sewn to the edges of the incisions that had been made in the perineum, forming the neovaginal introitus. The mould was removed one week later and the newly created vagina was irrigated with diluted $(1 \%)$ povidone-iodine solution and normal saline, consecutively. The term 'regular mould users' is used for patients who complied with instructions and used the mould continuously for the first three months. During this period, they were to remove the mould for only short periods of time for vaginal irrigation. After the first three months, the patients were allowed to engage in sexual intercourse. For the following three months, mould use was incrementally decreased until the patient kept the mould in the new vaginal cavity for only $1 \mathrm{~h}$ per day. Six months after the surgery, if the patient engaged in regular sexual intercourse, the frequency of the mould use was left to the discretion of the patient depending on the rate of sexual intercourse per week. Otherwise, the mould was kept in the vaginal cavity for $1 \mathrm{~h}$ three times per week.

\section{RESULTS}

The preoperative anatomical properties of 23 patients whose age varied from 13 to 36 years (mean 27.8 years) are summarized in Table 1. All patients had normal external genitalia in appearance except for one in whom clitoromegaly due to AIS was detected. This patient underwent an additional clitoroplasty procedure at the time of the vaginoplasty. The vagina was totally absent in four patients. In the remaining 19 patients, vaginal depth ranged from $1 \mathrm{~cm}$ to $4 \mathrm{~cm}$.

Twenty patients had total absence of the uterus and fallopian tubes. In two patients, the uterus and fallopian tubes were fully developed and, in only one patient, a rudimentary uterus was observed. Ovaries were not seen in two patients, one of whom had testicular feminization syndrome. In one patient with vaginal agenesis, Klippel-Feil syndrome was detected. This patient presented with a short, webbed neck, decreased range of motion in the cervical spine and a low hairline with cervical spine fusion.

The pre- and postoperative findings are presented in Table 2 . The mean follow-up period after surgery was 60 months (range 18 to 118 months). Preoperative vaginal length varied from $0 \mathrm{~cm}$ to $4 \mathrm{~cm}$ (mean length $0.82 \mathrm{~cm}$ ) and postoperative vaginal length varied from $4 \mathrm{~cm}$ to $11 \mathrm{~cm}$ (mean length $7.8 \mathrm{~cm}$ ). Successful skin graft take and pseudomucinous metaplasia of the grafts were achieved in all patients. Nineteen patients $(83 \%)$ used the mould regularly and four $(17 \%)$ used it irregularly. Despite regular use of the mould, three of the patients required repeat surgery within two months due to a partial vaginal stricture. During the follow-up, no other complications, such as hemorrhages, infections, cheloid scar on the donor site or fistulas, were observed.

Among the 19 regular mould users, five did not engage in sexual intercourse, three of whom did not have a partner. Their mean vaginal length was $8.4 \mathrm{~cm}$ (range $6 \mathrm{~cm}$ to $11 \mathrm{~cm}$ ). Thirteen of 14 patients reported that they were engaging in satisfactory sexual activity with mild or no pain, and with good mucosal sensitivity; only one patient experienced severe pain during sexual intercourse. Conversely, two of four patients who used the mould irregularly experienced severe pain during sexual intercourse and their mean vaginal length was $6 \mathrm{~cm}$ (range $4 \mathrm{~cm}$ to $8 \mathrm{~cm}$ ).

One of the patients who had a normal uterus, fallopian tubes and ovaries gave birth via caesarean section at 36 weeks' gestation three years after vaginoplasty.

\section{DISCUSSION}

Because there are several available techniques to treat vaginal agenesis, the patient's medical history, preference, lifestyle and underlying condition, along with the surgeon's capability, play an important role in choosing the correct approach. Although there is no consensus on which technique to use, the modified McIndoe has been the preferred method for many clinicians. We choose to use it because of its low complication rate and relative simplicity. In addition, the McIndoe technique does not require a transabdominal approach, which mitigates surgical risk. However, it does have disadvantages including scarring in the grafted area, cheloid formation and infection risk.

The Vechietti technique requires traction rather than dilation to create the neovagina. Although, it is usually performed laparoscopically, due to the potential need to switch to laparotomy, the complication rate is high. In addition, traction of the 'olive' at the vaginal dimple can be very painful and may not be easily tolerated by the patient $(5,11,12)$. The Vechietti technique was used by Fedele et al (13) and Bruker et al (14) in 110 and 101 patients, respectively. The achieved vaginal length was well within limits and nearly $60 \%$ of patients engaged in sexual intercourse without dyspareunia. The sexual satisfaction rate reported in the literature is approximately $80 \%$ to $90 \%$ when using the McIndoe technique $(15,16)$, which is higher than the previously mentioned rate achieved with Vechietti. In our case series, the sexual satisfaction rate was approximately $93 \%$ (13 of 14 patients) in patients who used the mould regularly.

Another surgical approach to treat vaginal agenesis is to create a new vagina using a peritoneal flap. This approach was first used by Davydov in 1969 (17). This approach can be performed laparoscopically or laparotomically. However, there is a significant risk of damage to the bladder and/or ureter, and risk of peritonitis and vesicovaginal fistula formation (18).

Another approach is vaginoplasty using intestinal grafts. The procedure has advantages such as not needing dilation after surgery, a natural lubricant effect and lack of shrinkage or narrowing after surgery. On the other hand, due to the need for laparotomy, the risks of 
TABLE 2

Clinical features and examination findings in 23 patients who underwent long-term follow-up

\begin{tabular}{|c|c|c|c|c|c|c|c|c|c|}
\hline \multirow[b]{3}{*}{ Case } & \multirow{3}{*}{$\begin{array}{l}\text { Age at } \\
\text { surgery, } \\
\text { years }\end{array}$} & \multirow{3}{*}{ Genital anatomy } & \multirow{3}{*}{$\begin{array}{c}\text { Preoperative } \\
\text { vaginal length, } \\
\text { cm }\end{array}$} & \multicolumn{2}{|c|}{ Mould use } & \multirow{3}{*}{$\begin{array}{l}\text { Sexual } \\
\text { intercourse }\end{array}$} & \multirow{2}{*}{\multicolumn{2}{|c|}{ Postoperative }} & \multirow{3}{*}{$\begin{array}{l}\text { Follow-up, } \\
\text { months }\end{array}$} \\
\hline & & & & \multirow{2}{*}{$\begin{array}{l}\text { Duration, } \\
\text { months }\end{array}$} & \multirow[b]{2}{*}{ Frequency } & & & & \\
\hline & & & & & & & Vaginal length, cm & Complications & \\
\hline 1 & 14 & $\begin{array}{l}\text { Absent uterus, vagina and } \\
\text { ovaries }\end{array}$ & 1.4 & 74 & Regular & None & 7 & & 108 \\
\hline 2 & 32 & $\begin{array}{l}\text { Rudimentary uterus, absent } \\
\text { vagina }\end{array}$ & 1 & 50 & Irregular & $\begin{array}{l}\text { Yes, severe } \\
\text { pain }\end{array}$ & 5 & & 75 \\
\hline 3 & 28 & Absent uterus and vagina & 2 & 6 & Regular & Yes, mild pain & 7 & & 79 \\
\hline 4 & 31 & Absent uterus and vagina & 1.5 & 36 & Regular & $\begin{array}{l}\text { Yes, without } \\
\text { pain }\end{array}$ & 9 & & 118 \\
\hline 5 & 34 & Absent uterus and vagina & 4 & 6 & Regular & $\begin{array}{l}\text { Yes, without } \\
\text { pain }\end{array}$ & 10 & & 65 \\
\hline 6 & 25 & Absent uterus and vagina & 1.5 & 6 & Regular & Yes, mild pain & 7 & $\begin{array}{l}\text { Partial vaginal } \\
\text { stricture }\end{array}$ & 68 \\
\hline 7 & 34 & $\begin{array}{l}\text { Absent uterus, vagina and } \\
\text { ovaries }\end{array}$ & 1 & 9 & Regular & $\begin{array}{l}\text { Yes, without } \\
\text { pain }\end{array}$ & 9 & & 59 \\
\hline 8 & 32 & Absent uterus and vagina & Agenesis & 40 & Regular & None & 8 & $\begin{array}{l}\text { Partial vaginal } \\
\text { stricture }\end{array}$ & 52 \\
\hline 9 & 33 & Absent uterus and vagina & 2 & 2 & Regular & $\begin{array}{l}\text { Yes, without } \\
\text { pain }\end{array}$ & 9 & & 55 \\
\hline 10 & 29 & Absent uterus and vagina & 1 & 25 & Regular & Yes, mild pain & 8 & & 44 \\
\hline 11 & 26 & Absent uterus and vagina & Agenesis & 32 & Regular & $\begin{array}{l}\text { Yes, without } \\
\text { pain }\end{array}$ & 10 & & 44 \\
\hline 12 & 16 & $\begin{array}{c}\text { Absent vagina, normal } \\
\text { uterus and ovaries }\end{array}$ & 2 & 40 & Regular & $\begin{array}{l}\text { Yes, without } \\
\text { pain }\end{array}$ & 10 & & 53 \\
\hline 13 & 36 & Absent uterus and vagina & 1.2 & 12 & Irregular & $\begin{array}{l}\text { Yes, severe } \\
\text { pain }\end{array}$ & 6 & & 54 \\
\hline 14 & 30 & Absent uterus and vagina & 1 & 6 & Irregular & Yes, mild pain & 8 & & 58 \\
\hline 15 & 13 & Absent uterus and vagina & 2 & 16 & Regular & None & 8 & & 20 \\
\hline 16 & 23 & Absent uterus and vagina & 1 & 19 & Regular & $\begin{array}{l}\text { Yes, without } \\
\text { pain }\end{array}$ & 9 & & 18 \\
\hline 17 & 25 & $\begin{array}{l}\text { Absent uterus, vagina and } \\
\text { ovaries }\end{array}$ & 1.5 & 32 & Irregular & $\begin{array}{l}\text { Yes, severe } \\
\text { pain }\end{array}$ & 4 & & 22 \\
\hline 18 & 33 & Absent uterus and vagina & 1 & 18 & Regular & Yes, mild pain & 6 & & 26 \\
\hline 19 & 21 & Absent uterus and vagina & 2 & 36 & Regular & None & 7 & & 67 \\
\hline 20 & 27 & $\begin{array}{l}\text { Absent uterus, vagina and } \\
\text { ovaries }\end{array}$ & Agenesis & 42 & Regular & None & 9 & & 55 \\
\hline 21 & 26 & $\begin{array}{l}\text { Absent vagina, normal } \\
\text { uterus and ovaries }\end{array}$ & 1 & 6 & Regular & $\begin{array}{l}\text { Yes, without } \\
\text { pain }\end{array}$ & 11 & & 56 \\
\hline 22 & 16 & $\begin{array}{l}\text { Absent uterus, vagina and } \\
\text { ovaries }\end{array}$ & Agenesis & 9 & Regular & $\begin{array}{l}\text { Yes, severe } \\
\text { pain }\end{array}$ & 6 & $\begin{array}{l}\text { Partial vaginal } \\
\text { stricture }\end{array}$ & 77 \\
\hline 23 & 29 & Absent uterus and vagina & 1 & 6 & Regular & Yes, mild pain & 9 & & 89 \\
\hline
\end{tabular}

serious infection, intestinal stenosis, dehiscence, and fistula formation preclude it as a first choice for many surgeons. Additionally, vaginas created with intestinal grafts will be less sensitive and prone to produce significant mucous. Therefore, the patient may need to use sanitary pads continuously. There is also a rare risk of malignancy (19-21).

According to the results of our study, to achieve painless and satisfactory sexual intercourse postoperatively, proper and regular mould use is of the utmost importance, especially in patients who engage in irregular or no sexual intercourse, and use the mould regularly for longer periods of time. Interestingly, none of our patients who had a postoperative vaginal length $\geq 8 \mathrm{~cm}$ experienced significant dyspareunia. This may be because of the potential relationship between indications of dyspareunia and vaginal length. However, the success of the surgery is not necessarily correlated with the length of the postoperative neovagina. A successful surgery indication is creating a new vagina with adequate length that is also functional and sensitive. Therefore, successful metaplasia in the graft mucosa also plays an important role in the sensitivity and elasticity of the newly created vagina.
Our patients used specially designed, rigid moulds with different lengths and widths. There are also moulds constructed from soft materials that can be used postoperatively. Soft moulds are constructed from polyethylene bags or condoms and filled with soft material, whereas rigid moulds are made from silicone or polystyrene. In the literature, there is not an adequate number of studies that compare the outcome of soft versus rigid moulds. Whichever mold is used, it should not cause too much pressure on the vagina walls and not create empty spaces to prevent hematoma development. It should have a passage in the centre for drainage purposes and should be easily inserted and removed.

A uterus is absent in $2 \%$ to $7 \%$ of patients with vaginal agenesis (22). In our study, only two patients had normal uterine anatomy. Spontaneous pregnancy is possible if normal ovaries, uterus and fallopian tubes exist. In such cases, special care must be devoted to preserve the uterus and connect it properly to the new vagina. One of our patients with isolated vaginal agenesis became spontaneously pregnant three years after the surgery and delivered a healthy baby by cesarean section. Because of the isolated vaginal agenesis, the 
patient had a healthy cervix, which prevented the postoperative ascension of genitalia or urinary infection risk. When the cervix and vagina are not developed normally due to an anomaly in patients with a normal uterus, hysterectomy can still be indicated even after a successful vaginoplasty because it is difficult to make the cervix permeable without serious complications $(23,24)$. In addition, the probability of pregnancy is extremely low in such patients $(23,24)$.

\section{REFERENCES}

1. Karim RB, Hage JJ, Dekker JJ, Schoot CM. Evolution of the methods of neovaginoplasty for vaginal aplasia. Eur J Obstet Gynecol Reproduct Biol 1995;58:19-27.

2. Busacca M, Perino A, Venezia R. Laparoscopic-ultrasonographic combined technique for the creation of a neovagina in MayerRokitansky-Kuster-Hauser syndrome. Fertil Steril 1996;66:1039-41.

3. Vecchietti G. [The neovagina in the Robitansky-Kuster-Hauser syndrome]. Revue medicale de la Suisse romande. 1979;99:593-601.

4. Laffargue F, Giacalone PL, Boulot P, Vigouroux B, Hedon B, Benos P. A laparoscopic procedure for the treatment of vaginal aplasia. Br J Obstet Gynaecol 1995;102:565-7.

5. Veronikis DK, McClure GB, Nichols DH. The Vecchietti operation for constructing a neovagina: Indications, instrumentation, and techniques. Obstet Gynecol 1997;90:301-4.

6. Davydov SN, Zhvitiashvili OD. Formation of vagina (colpopoiesis) from peritoneum of Douglas pouch. Acta Chirurgiae Plasticae. $1974 ; 16: 35-41$.

7. McIndoe A. The treatment of congenital absence and obliterative conditions of the vagina. Br J Plast Surg 1950;2:254-67.

8. Williams JK, Lake M, Ingram JM. The bicycle seat stool in the treatment of vaginal agenesis and stenosis. J Obstet Gynecol Neonatal Nurs 1985;14:147-50.

9. Banister JB, McIndoe AH. Congenital Absence of the Vagina, treated by Means of an Indwelling Skin-Graft. Proc Royal Soc Med 1938;31:1055-6.

10. Pratt JH. Vaginal atresia corrected by use of small and large bowel. Clin Obstet Gynecol 1972;15:639-49.

11. Makinoda S, Nishiya M, Sogame M, et al. Non-grafting method of vaginal construction for patients of vaginal agenesis without functioning uterus (Mayer-Rokitansky-Kuster syndrome). Int J Surgery 1996;81:385-9.

12. Fedele L, Bianchi S, Tozzi L, Borruto F, Vignali M. A new laparoscopic procedure for creation of a neovagina in MayerRokitansky-Kuster-Hauser syndrome. Fertil Steril 1996;66:854-7.

\section{CONCLUSION}

To optimize sexual comfort, the clinical management of women with vaginal agenesis must be multidisciplinary and individually tailored. Our findings suggest that the modified McIndoe technique is a simple, effective procedure for the treatment of vaginal agenesis, but proper mould usage after surgery remains the cornerstone of the treatment. Further research is needed to prospectively evaluate the clinical success of different surgical techniques.

13. Fedele L, Busacca M, Candiani M, Vignali M. Laparoscopic creation of a neovagina in Mayer-Rokitansky-Kuster-Hauser syndrome by modification of Vecchietti's operation. Am J Obstet Gynecol 1994;171:268-9.

14. Brucker SY, Gegusch M, Zubke W, Rall K, Gauwerky JF, Wallwiener D. Neovagina creation in vaginal agenesis: Development of a new laparoscopic Vecchietti-based procedure and optimized instruments in a prospective comparative interventional study in 101 patients. Fertil Steril 2008;90:1940-52.

15. Tolhurst DE, van der Helm TW. The treatment of vaginal atresia. Surg Gynecol Obstet 1991;172:407-14.

16. Mobus VJ, Kortenhorn K, Kreienberg R, Friedberg V. Long-term results after operative correction of vaginal aplasia. Am J Obstet Gynecol 1996;175:617-24.

17. Davydov SN. [Colpopoeisis from the peritoneum of the uterorectal space]. Akusherstvo i ginekologiia. 1969;45:55-7.

18. Giannesi A, Marchiole P, Benchaib M, Chevret-Measson M, Mathevet P, Dargent D. Sexuality after laparoscopic Davydov in patients affected by congenital complete vaginal agenesis associated with uterine agenesis or hypoplasia. Hum Reprod 2005;20:2954-7.

19. Ghosh TS, Kwawukume EY. Construction of an artificial vagina with sigmoid colon in vaginal agenesis. Int J Gynaecol Obstet 1994;45:41-5.

20. Schober JM. Cancer of the neovagina. J Pediatr Urol 2007;3:167-70.

21. Freundt I, Toolenaar TA, Huikeshoven FJ, Drogendijk AC, Jeekel H. A modified technique to create a neovagina with an isolated segment of sigmoid colon. Surg Gynecol Obstet 1992;174:11-6.

22. Hojsgaard A, Villadsen I. McIndoe procedure for congenital vaginal agenesis: Complications and results. Br J Plast Surg 1995;48:97-102.

23. Niver DH, Barrette G, Jewelewicz R. Congenital atresia of the uterine cervix and vagina: Three cases. Fertil Steril 1980;33:25-9.

24. Rock JA, Schlaff WD, Zacur HA, Jones HW Jr. The clinical management of congenital absence of the uterine cervix. Int J Gynaecol Obstet 1984;22:231-5. 